\title{
CAN WE ACHIEVE A COLLABORATIVE COMMUNITY? ISSUES, IMPERATIVES, POTENTIALS
}

\author{
Ronald Lippitt \\ University of Michigan \\ Jon Van Til \\ Rutgers University Camden Colleqe
}

We live in an increasingly interdependent world, in increasingly interdependent nations, and in increasingly interdependent communities. Our effectiveness in these societal contexts would in all probability be enhanced if we knew how to work together for the achievement of mutually-shared goals. But voluntary collaboration is an unfamiliar skill for most individuals and groups. Efforts to cooperate are often ineffective and half-hearted.

It is the purpose of this special issue on Interagency Collaboration to address this common deficiency and to explore cases in successful collaboration. We are applied behavioral scientists in this issue: we know collaboration can work, and we aim to show how.

\section{THE PROCESS OF INTERAGENCY COLLABORATION}

The theoretical, case study, and applied papers presented in this issue demonstrate that the process of collaboration follows a set of typical steps. These steps may be seen as precondition, testing, initiation, definition, invigoration, and evaluation. Each may be described more fully.

Step One: Establishing the Preconditions of Collaboration

Collaboration begins with a dream, or a vision, or a fantasy, or an idea-about how something in the world would be better if two or more organizations were to work more closely together in resolving a problem of mutual concern. Without that vision, nurtured and articulated by someone somewhere in an organizational world of action, no collaboration will emerge.

The initiation of collaborative activity is both a highly personal and idiosyncratic event and one with structural determinants. As Charles Mulford shows 


\section{8 / JOURNAL OF VOLUNTARY ACTION RESEARCH}

in his comparative study of three towns, both the interdependency of organizations and their community environment will have an important effect on the likelihood of collaboration between organizations. But collaboration may also be initiated by the kind of conversation Larry Gamm details between two agency directors. Or it may emerge in an of fhand comment, possibly an intentioned one, such as the one that Rosenbaum and Nichols describe as preceding the Michigan collaboration. Surely the vision is affected by the situation: it is not a random event. But without the manifestation of the predisposition-without its articulation--the separation of agency persists.

\section{Step Two: Testing the Collaborative Waters}

The articulation of the collaborative potentiality may quickly be followed by a fuller exploration of the idea's viability. Four tests are suggested, and are more fully discussed by Robert Dye and John Wood in their article in this issue and their work elsewhere (National Juvenile Justice Program Collaboration) and by Eva Schindler-Rainman in her concluding contribution. These tests are:

1) Assuring that the proposed collaboration does not threaten "organizational domain." Organizations, like most of the rest of us, are highly conscious of the turf they control. In interacting with other organizations, an individual organization is likely to act so as to preserve or expand its domain. Only when new images of reward have become comfortable and acceptable is an organization likely to be willing to explore reductions in its domain. Such may accompany progress in collaboration, but it is unlikely to occur at the testing phase.

2) Assuring that the proposed collaboration does not threaten organizational autonomy. The point is closely related to the first. If coordination poses a threat to the autonomy of an organization, it is unlikely to receive any serious exploratory consideration.

3) Sketching an inage of potential "domain consensus." If collaboration is to be achieved, the collaborators will eventually need to agree on the terms of their mutual activity. Such "domain consensus" involves agreeing as to the clients to be served, the types of services to be offered, and the ways in which service might be jointly provided. If these outcomes cannot plausibly be conceived, it is unlikely that collaboration will occur.

4) Checking limits of pre-existing collaborative networks. If an organization is already fully engaged in a network of collaboration, effects will be felt on proposed collaborative ventures. It may be that there are limits to the magnitude of effective collaboration. It certainly is the case that existing arrangements will affect many possibilities that may be proposed.

\section{Step 3: Initiating the Idea of Collaboration}

From the very first conversation which broaches the possibility of collaboration, attention is required to the mood and setting of the exploratory discussions. The literature on failed collaboration is replete with instances in which parties to the process did not clearly see collaboration as a vehicle for problem-resolution. As Ortiz demonstrates in his paper, organizations may remain chary of the initiator of collaboration. Distrust and suspicion of empire-building may be real, and will almost always retard effective interaction. 
The initiating organization will be more likely to succeed in effecting collaboration if it can demonstrate the credibility of its problem-solving commitment. Its chances of winning teammates increases further if it can show that collaboration will extend the amount of resources available to each potential collaborator.

A third task of the initiator is to share the thinking that led to the initiation of the vision. Why does it seem plausible that domains will not be threatened, that autonomies can be preserved, that domain consensus can be achieved, and that prior networks will not restrain the collaboration? If the vision can be communicated, and then shared, the collaborative venture has been successfully initiated.

\section{Step 4: Defining the Collaborative Venture}

This step requires that clear definitions of member and team roles be developed. Collaboration will be most effective if a clearly identified "collaborative team" be developed. This team works best if it consists of individuals of relatively high status in their own organizations. It also helps if they carry the full respect of their colleagues both within and without their own respective shops.

As the coordinating team comes into existence, it must be able to demonstrate that it can, when necessary, act independently of the several organizational loyalties that its members carry. Team members must demonstrate their freedom from the limits of special organizational advocacies. They need to be able to take third party positions in the case of conflicts; they need to be able to initiate "win-win" solutions to the thorny problems that will arise.

The selected members of organizations who come to form the linking mechanism must develop a loyalty to the core group strong enough to cope with the competing pressures that issue from their own organizations. They come to take on a new identity--that of the "boundary spanner"--1oyal to their own organization but possessed of the broader vision that comes from working closely with trusted colleagues of somewhat different experience and perspective.

As they learn to trust and work with each other, the group of boundary spanners begin to draw the blueprint, or social contract, of their collaborative venture. Can the collaborative effort be fully cooperative? Yes, where a pattern of consensus on issues and outcomes begins to emerge. Are there times in which contest or competition becomes a mode of collaborative activity? Yes, when organizational interests come into areas of difference, and can only be resolved by a position that, for the time being, advantages some collaborators more than others.

\section{Step 5: Invigorating the Collaborative Process}

Collaboration, like any marriage or liaison, has its low points and pitfalls. Surmounting them requires insight, patience, sensitivity, and perspective. Obviously, no collaborative experience is identical to any other. But we offer the following generalizations as helpful to the invigoration of future collaborative ventures:

1) The greater the complementarity of functions (as contrasted to similarity) between the collaborative venture and the individual members of the consortium, 


\section{0 / JOURNAL OF VOLUNTARY ACTION RESEARCH}

the greater the likelihood of cooperative action. Collaboration is most effective when it permits new problems to be defined and solved with newlycombined resources.

2) The larger the consortium, the more likely it is that an uncooperative coalition will develop within it. This is not to argue against broad-based collaboration, but simply to warn that it is often not an easy process to manage or facilitate.

As collaboration proceeds, the leaders of the coordinating team will find that they themselves have changed. Their ideas, their views of their own and other organizations will all undergo some degree of change. Research has shown that these boundary roles become increasingly influential, less predictable and routine, and more relied upon for innovations as they develop.

There will be times when the entire enterprise will be challenged from within. In such periods, the very existence of the collaboration will come to be questioned. Some groups that had come to hope that they would be able to work together will find that the next meeting is simply never called. But other ventures will recover and continue with their efforts to achieve the dream they continue to affirm.

\section{Step 6: Evaluating the Collaborative Experience}

Collaborative ventures should be formally and informally evaluated even more frequently than more established organizational initiatives. The validity of the initial dream that brought the collaboration into existence requires renewal and review. Even more important, the contributions that may have emerged as gains, whether anticipated or unanticipated, of the process need to be recorded and shared both back home and in the collaborative milieu. of course, not all collaborative experiences do meet their goals; nor do all create serendipitous gains that no one anticipated. Those collaborative ventures should be abandoned, its participants knowing that another day may bring another dream.

\section{CONTEXTS FOR NON-COLLABORATION}

It is certainly not surprising that collaboration is often not considered, attempted, or successfully completed. The contexts for non-collaboration are many and deeply-rooted in our society. As Larry Gamm shows so clearly in his extensive review of the literature on interorganizational relations in this issue, collaboration often extends into complex interorganizational networks. Many established thoughtways and behaviors must be changed if successful collaboration is to be achieved.

Among the principal societal barriers to collaboration seem to us to be the following:

1. Deeply ingrained into American culture is an ethos in which competition and independence is the expectation, the way to survive, the means of growth, the path to achievement and success. Often these values and behavior patterns are based on assumptions of limited resources or exclusive technology to be competed for. Self-esteem is based on the mobilization of the necessary skills to "beat the others." This orientation, which is basic to political, economic, and organizational life, is supported and trained for by our educational 
recreational (e.g., sports), and family institutions.

2. To maintain "fair play", many of our public and private enterprises of human service, education, and technology are vigorously separated from each other by legal and administrative restraints. So another theme emerges, distruct of unfair competition. Maintaining one's advantage requires keeping oneself separate. It also means, in many cases, duplicating services provided by others, or underserving clients or constituencies because limited resources have been needlessly fragmented. It may seem a paradox that the increasingly complex enterprises of society require intricate teamwork, but this stops at the boundaries of each competing unit.

3. "It takes too long to bring them along" is another expression of a rationale for non-collaboration. If some of the parties are too ignorant, uneducated, or backward, we can't expect them to do their part in any collaboration, and we can't be expected to hold up progress by including them.

4. Turfdom is a very important aspect of the maintenance and survival of our agencies and organizations. Agencies define themselves in terms of "our clients", "our program", "our loyal members", "our volunteers", "our fund drives." They maintain a mutual collusion of non-collaboration.

5. In the socialization of our young a strong emphasis is put on interdependence, "doing your own thing", mine vs yours, protecting your rights, and building a strong ego, i.e., self-identity or strong boundaries of the self vs others. There are strong contrasts here to other cultures and childrearing orientations. For example, the Buddhists place strong emphasis on interdependence and "egolessness" as a condition of "oneness" of persons with each other. Oriental practices put an emphasis on collective wisdom as contrasted with ours.

6. In this context of valued independence and self-actualization the idea of negotiation and compromise is basically a negative value. "To compromise" means having to give in or give up some of your enlightened position for a more mediocre result. Compromising is a reluctant necessity rather than a potential for creative emergence of an outcome superior to what anyone started with, which is the assumption in some Oriental groups we have studied.

7. Another posture of distrust of the value of collaboration is expressed by all the negative comments about committees, "the trouble with democracy is committees", "a camel must have been put together by a committee", "the fewer committee meetings the better", "too much of my day is used up in useless committees." There is a widely shared assumption that people cannot be trusted to collaborate with each other effectively in committees.

So we see that at the levels of cultural, political, economic, intergroup, and interpersonal dynamics there are barriers to cooperative interaction and the blending of intelligence and energy. And we communicate these values and assumptions to our young through education and by our modelling.

The case material presented in the studies by Isidro Ortiz, Ira Rosenbaum and Robert Nichols, and Sam Quick, Robert Flashman, and Arlene Gibeau in this issue illustrate many of these barriers. The Hispanic community organization Ortiz studied was wary of collaboration enforced as a condition of funding by governmental officials. Ortiz concludes that if collaboration is to be facilitated, political leaders must be limited in their ability to use funding 


\title{
12 / JOURNAL OF VOLUNTARY ACTION RESEARCH
}

\author{
to undermine the formation of coalitions.
}

Quick, Flashman, and Gibeaux note that collaboration is subject to internal strains as well. Who gets credit (or takes credit) for the gains of collaboration? How do different structures, paid and volunteer, become integrated into a collaborative model? How are citizen initiatives melded into bureaucratic structures? Some progress is noted on these questions in the Kentucky case of SOS learning systems, but the problems remain not fully resolved as the case study was being prepared.

Rosenbaum and Nichols study the collaboration between two agencies, a public welfare agency and a Child Guidance Center, which had worked at cross-purposes for years in a Michigan town. They document the existence of organizational fantasies held by staff of both agencies. Often, patients became the carriers of messages of organizational tension between the two warring agencies.

But the seeds for nurturing the values and skills of collaboration are also present where there is pride in teamwork, belief in the full utilization of talents, and a pragmatic approach to problem-solving and pitching in to give help when it is needed. That these well-established American values may be productively drawn upon is indicated by each of the case studies.

Dye and Wood, in their analysis of the growing collaboration between over twenty national youth-serving organizations, point to the importance of creating the collaborative venture as one that threatens no member but enhances all. Within far more constrained limits, the process Ortiz documents shows that collaboration between ethnic groups may be the first step toward the development of lines that extend beyong the community. First, the fear that collaboration means the final loss of autonomy must be confronted and resolved.

Once the collaborative process begins, it can be exhilarating, as Rosenbaum and Nichols describe the Michigan process. Real problems replace fantasies; the collaborating organizations become more productive, more able to meet the needs of their clients. And this, the authors all agree, is the "bottom line" of collaboration: not that it feels good to do it (which it usually does), but that it enables more and better work to be accomplished. Successful collaboration meshes process with product.

There are a variety of reasons why we are well-advised to recognize the values and payoffs of collaboration, and bend our efforts toward achieving the skills of collaboration and teaching them to our young. Here are a few of the reasons which seem important to us.

\section{WHAT COLLABORATION CAN PROVIDE}

\section{A WAY TO COPE WITH INCREASING COMPLEXITY}

It has been noted that in each succeeding decade there is increasing complexity to the technical and social problems which must be coped with. Corresponding increases are required in the sophistication of our methodologies for problemsolving, though there is a very slow increase in our readiness, motivation, and capability to use these resources adequately to cope with our challenges. A study of participation in significant inventions shows that between 1900-1910 an average of 1.8 brains were involved in the creation of significant inventions. Between 1960-1970 the number of participants had risen to an average of 15 per 
invention. The need to blend professionalized interdisciplinary knowledge of many types has clearly become a critical imperative in solving all types of problems--technical, economic, political, and social.

\section{A WAY OF MEETING EXPANDING EXPECTATIONS, NEEDS, AND DEMANDS OF HUMAN SERVICES}

Consumers, clients, and learners are all becoming more informed and sophisticated about expressing their needs, and more aware of the types of resources and services that have been developed and could be available to them. The gap between these "images of possibilities" and actual available services has been widening rapidly. Patients in the hospital, students in the classroom, consumers in the marketplace, citizens in the community are increasingly articulate about their needs and expectations. These service demands have been accelerating far more rapidly than the development of budgetary and personnel resources to meet these needs. It is apparent that human, technological, and financial resources must be integrated and utilized far more effectively than is possible by the present separated and fragmented human service function of both the public and the private sectors. Accountability for duplication of services and inefficiencies of program efforts are a focus of concern and critique. Doing more with less is one of the imperatives of the taxpayer's revolt. Improved collaboration is one of the most effective patterns of response.

\section{INVOLVING UNUSED HUMAN RESOURCES}

The greatest single pool of unused resources for meeting human service needs is the pool of untapped volunteer time and energy. The Gallup Poll indicates that the large majority of Americans above the age of 14 are ready and willing to give volunteer time for community service. Relatively few have been involved. This is to a high degree the result of the hesitation and caution of the professional practitioners who involve volunteers in a wide variety of collaborative efforts. But the imperative is clear and pressing. Volunteers must be asked to collaborate in meeting the great range of unmet service needs.

\section{SHARED USE OF FACILITIES AND PROGRAM RESOURCES}

There is increasing recognition of the fact that humanistic and economic services must be 1 ocal, i.e., "where the people are", and must be oriented to the whole person, or group, rather than some specialized aspect (e.g., financial needs, nutrition needs, health service needs, mental health, etc.). This means that specialized resource persons must team up and must be located in local facilities where they can interact easily with their clients. This, in turn, implies the development of collaboration in the use of existing facilities which may have been built as the turfdom of a particular agency. It also means the development of service teams that are able to relate effectively to the whole person, or to the total group or total neighborhood, effectively blending their special skills.

\section{IMPROVED UTILIZATION OF FUNDS AND PERSONNEL}

The jealous separation of public and private funds and personnel functions have an important legal and political history and legitimacy. But just as professional and volunteer energy must be merged to cope with complex problems and accelerated demands, so must public and private financial resources and personnel be teamed for effective problem-solving efforts. When the courts and 


\section{4 / JOURNAL OF VOLUNTARY ACTION RESEARCH}

the private youth-serving agencies have merged their efforts to develop creative and effective alternatives in the field of juvenile justice, there has been a great increase both in effective humaneness and cost savings. When the mayor's office, the Junior League, the Chamber of Commerce, the Community College, local business leaders and unions have combined to sponsor citizen involvement in community goal-setting, there has been a great enhancement of the clout needed to encourage widespread participation. When the question was asked, "Who are the partners needed to provide the complementary resources and generate the leverage for action?", important new dimensions of collaboration were identified as imperatives. This question also of ten points to the necessity of vertical collaboration between the resources in the communities and at the state and federal levels.

\section{ISSUES WAITING FOR COLLABORATIVE PROBLEM-SOLVING}

In every community, as well as at the state and national level, there are a series of challenging and complex problems which can only be tackled effectively by new patterns of collaboration. Among these issues are the following:

\section{EDUCATING AND SOCIALIZING THE YOUNG}

The growing of our young is typically fragmented, inconsistent, discontinuous, and inadequate. In every community there are six or seven different clusters of adults who have been delegated, or self-appointed, to take responsibllity for some aspect of the socialization function. For example, there are those who are delegated to provide educational experiences, those responsible for legal supervision and sanctions, those responsible for religious development and values education, the providers and leaders of recreational and leisure time activities, the protectors and maintainers of health, those responsible for occupational training and apprenticeship, the models and guides of family life education, orienters to the norms and practices of peer culture, and so on.

In every community funds are wasted in duplication of services and efforts, while other significant populations are neglected. The lack of coordination and consistency in the patterns of interaction with the young result in serious confusion and negating of the efforts of the well-meaning. More wastage arises from the typical lack of involvement of the young in clarifying goals and development of shared commitments and responsibilities. In other words we have two issues of collaboration here, one of collaboration between the sectors of the socialization community, the second, of lack of collaboration between the generations.

\section{SEPARATED PLANNING}

Most of the organizations and agencies of a community have a variety of interdependencies, e.g., in regard to sources of funding, client populations, program resources, and volunteer helpers. But most of these organizations act as though they were independent as they attempt to do goal-setting and planning. Even though it is often the case that the same community leaders serve on the policy-making boards of two or more agencies and groups, there is very seldom any collaboration at the point of planning goal priorities and planning for implementation. 


\section{LACK OF COMMUNICATION AMONG LEADERS}

Many of the key local leaders in the various parts of the community enterprise do not know each other, and do not communicate easily. They are typically quite uninformed about each others' activities and plans and problems. The leadership have discovered that they can set a high degree of consensus among nominators as to who the community leaders are. They can identify each other. But about each others' activities and objectives there is a high level of ignorance, and when they are convened there is evidence and collaboration.

\section{LACK OF COLLABORATION ABOUT FUNDING}

Many available sources of funding are not attracted by the non-collaborative posture of many organizations and agencies that seek to tackle a particular problem. They avoid providing funds to any one organization "because then all the others will be asking" and they perceive a lack of readiness among agencies to make efficient collaborative use of their funds in joint projects. The assumption of a limited pie of available money, so if they get a bigger slice, we' 11 get a smaller one, is a fatal assumption. There is much evidence that the total pie can be expanded for everyone if meaningful collaboration can be developed and advanced.

\section{DEVELOPMENT OF INNOVATIVE SOLUTIONS}

Every community is full of significant small problem-solving demonstrations. They represent a rich resource of social invention which typically remains unidentified, unevaluated, and with no impetus or mechanism for dissemination. There are various reasons for lack of dissemination in the performance of human services; it is found in the lack of dissemination of innovations from one agency to another, from one community to another, for identifying significant innovations and spreading them is one of our most serious issues.

\section{LIMITED USE OF AVAILABLE VOLUNTEER TIME AND ENERGY}

We have already referred to the caution and ineptness of professionals in recruiting and utilizing the large pool of available volunteer energy. Not only does this mean a serious diminution of the extent and quality of service, but it represents a basic lack of opportunity for many persons who need the growth opportunities provided by significant volunteer experience. There is particular evidence that the young and the elders need the opportunities to be needed, involved, and influential in significant community service activities.

\section{LACK OF INVOLVEMENT OF THOSE WHO ARE SERVED IN GOAL-SETTING AND PROBLEM- SOLVING}

Although most of us understand the principle that to be an intelligent and effective utilizer of services one has to have an opportunity to be involved in designing the needs and the goals, still we are tragically delinquent in implementing that understanding. We also perceive that many teachers have not discovered effective ways of involving learners in clarifying learning aims and arriving at two-way commitments for participation in the learning process. In relatively few hospitals are patients actually involved in the formulation of treatment and rehabilitation goals and plans. Very few welfare clients have been actively involved in goal-setting. The same can be said of young prisoners, or of citizens, who usually have no involvement in doing long-range planning for 
their city. This is one of our greatest challenges.

\section{SOME PROMISING TRENDS IN THE DEVELOPMENT OF COLLABORATION}

With regard to almost all of the issues listed above, there are isolated examples, often a series of separated ones, of innovative approaches to coping with the issue. The model future of 10 or 20 years from now is already here among us someplace. In some cases there are clear, rapidly-moving trends which are considerably more than isolated examples. Here are a few of what seem likely to be among the most promising trends in the development of significant collaboration.

1. There is a growing movement in the creation of a variety of national coalitions, consortia, and councils between national organizations. We observe a continuing search for significant coalitions among labor, environmental interests, and social change organizations. Several significant consortia have been established among national organizations concerned with the development of voluntarism. Others are concerned with developing approaches to the energy problem, child abuse, women's rights, and to the protection of the environment. The national youth-serving organizations analyzed by Dye and Wood have demonstrated significant collaboration in coping with problems of juvenile justice and youth development. In some of these cases the alliances include collaborators from both the public and the private sectors, and from the business community as partners in the same collaborative effort.

2. At the local community level we are observing a great increase in communitywide coordinating councils responsible for designing and monitoring collaboration in a variety of areas. Some coordinating efforts have focused on such area-wide problems as transportation, area-wide government, downtown development, housing re-development, and beautification. Other collaborations are focused on improvement of services to the elderly, or to youth, or to the handicapped. There seems to be some evidence of a rebirth of collaborative efforts focused on neighborhood development.

3. There is a significant increase in interagency collaboration in the generating of joint program proposals and funding requests, and the recruiting and training of volunteers. In some of these collaborations we are seeing new partners, such as joint planning by the school system and private youth-serving agencies for the design of after school programs for youths, using both school and agency facilities.

4. One of the most vigorous trends is the development of community resource directories, referral services, resource centers, and volunteer bureaus. In some cases the city government is taking leadership in the recruiting and training of community service volunteers and the development of the computerized human resource inventory. This is a trend we believe will develop very rapidly in the next few years.

5. There is a growth of interest in citywide goal-setting and planning conferences. Our involvement in over 75 of these in the last few years has given us a chance to observe the great release of excitement and creative intelligence which flows from this kind of opportunity for citizens to define priorities and to become involved in task forces which integrate the energy of political leadership, professional staff members, and "unorganized" citizens 
who have a great deal to offer in the way of experience and time. The resources of elder citizens have been an important component (See Cooper and Alderfer, 1978)

6. Many institutions of higher education, faced with the challenge of the changing composition of their student bodies, are putting more attention to their role in the community and are initiating leadership of comnunity issue forums, leadership training, and consultation to community organizations and agencies. We can expect this kind of initiative to develop rapidly during the next few years.

7. Finally, it is important to call attention to the trend to pay attention to trends. Futuring is in rapid development in all sectors and at a11 levels of society. This interest includes those who are protectively concerned with survival and therefore want to get as much wisdom from experts as they can about the probabilities of various alternate futures so that they can plan to adjust to and to exploit the share of things to come. It also includes the many others who are viewing the challenge of clarifying a preferred future as a basis for exploring consensus among the members of an organization or community. Building upon the basis of this exploration, the creative energies of the collaborators may be mobilized toward planning strategies and steps of action which will facilitate the desired future.

In observing this process in many contexts we have come to the conclusion that articulating and prioritizing a preferred future is one of the most effective means of generating a motivated and informed collaboration, in contrast to the usual divisiveness and defensiveness that develops when the effort is to build collaborative problem-solving through focusing on current problems. Problems also receive focus in the futuring process, but they become set in the context of how barriers may be overcome, and agreed-upon goals may be achieved. In the final paper in the present collection, our colleague Eva Schindler-Rainman describes in some detail just how this process usually works. And work it often does. Interagency collaboration can be a powerful tool for program development and social change.

\section{REFERENCES}

National Juvenile Justice Program Collaboration (New York: National Assembly of National Voluntary Health and Social Welfare Organizations, Inc.) n.d. COMMUNITY COLLABORATION: A Manual for Voluntary Sector Organizations.

Cary L. Cooper and Clayton Alderfer

1978 ADVANCES IN EXPERIMENTAL SOCIAL PROCESSES, Vol. I (New York: John Wiley \& Sons). 